\title{
Medical Image of the Week: Bilateral Pneumothorax, Pneumomediastinum, and Massive Subcutaneous Emphysema
}

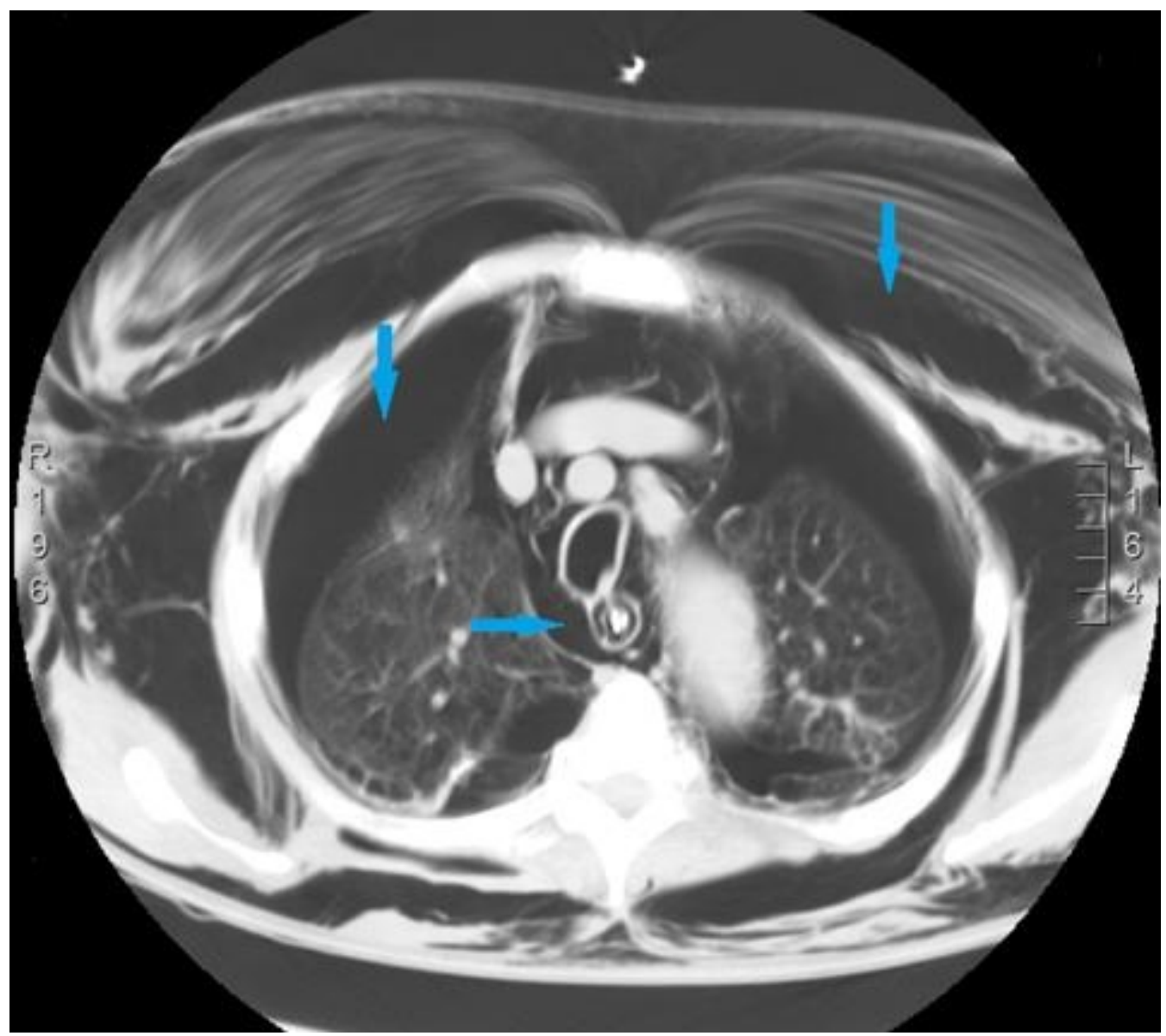

Figure 1. Computed tomography of the thorax showing subcutaneous air dispersed in the adipose tissue, separating the fascia of the pectoralis major, and the delineation of

its fibers (top arrow), pneumothorax compressing the lung (middle arrow), and pneumomediastinum compressing the trachea (bottom arrow).

An 80 year old man with chronic obstructive pulmonary disease (COPD) presented to the emergency department with respiratory distress and poor oxygen saturation. Physical exam revealed an obese male in respiratory distress with poor air entry bilaterally and scattered wheezing. His chest, neck, tongue, and lips were swollen. The patient was intubated for respiratory failure, felt to be due to angioedema. His oxygen saturation immediately improved, however the patient developed progressive swelling throughout his body including his eyelids, fingers and toes. Diffuse crepitus was felt on palpation. Chest radiography and computed tomography (CT) of the chest revealed large bilateral pneumothoraces, pneumomediastinum, and subcutaneous emphysema (Figure 1). Bilateral chest tubes were inserted with re-expansion of both lungs. Over the next several days his respiratory parameters improved, with full re-expansion of the lungs and reabsorption of the pneumomediastinum and subcutaneous emphysema. The patient was extubated successfully and was discharged in good health. 
Bilateral spontaneous pneumothorax, pneumomediastinum, and subcutaneous emphysema (SCE) are complications that may occur individually or rarely concomitantly, as in our case, during COPD exacerbations (the exact occurrence rate has not been described in the literature) (1-3). Bilateral spontaneous pneumthorax occurs in $1.9 \%$ of all spontaneous pneumothorax (4). The diagnosis is made with physical exam and appropriate imaging. Depending on the tension physiology, these conditions may lead to rapid respiratory failure and decreased cardiac output, especially when complicated by pulmonary barotrauma during mechanical ventilation $(5,6)$. In severe cases, SCE may involve respiratory compromise by compressing the trachea.

The early diagnosis with meticulous physical exam and relevant testing is essential, in order to immediately initiate appropriate management, and hence avoid the lifethreatening complications associated with spontaneous pneumothorax, pneumomediastinum, and subcutaneous emphysema.

Zavier Ahmed MD, Manpreet Singh MD, Ricardo Lopez, MD Icahn School of Medicine at Mount Sinai Queens Hospital Center 82-68 164th Street Queens, NY

\section{References}

1. Williams-Johnson J, Williams EW, Hart N, Maycock C, Bullock K, Ramphal P. Simultaneous spontaneous bilateral pneumothoraces in an asthmatic. West Indian Med J. 2008;57(5):508-10.[PubMed]

2. Karakaya Z, Demir S, Sagay SS, Karakaya O, Ozdinc S. Bilateral spontaneous pneumothorax, pneumomediastinum, and subcutaneous emphysema: rare and fatal complications of asthma. Case Rep Emerg Med. 2012; 242579. [PubMed]

3. Limthongkul S, Wongthim S, Udompanich V, Charoenlap P, Nuchprayoon C. Spontaneous pneumothorax in chronic obstructive pulmonary disease. J Med Assoc Thai. 1992;75(4):204-12. [PubMed]

4. Athanassiadi K, Kalavrouziotis G, Loutsidis A, Hatzimichalis A, Bellenis I, Exarchos N. Treatment of spontaneous pneumothorax: ten-year experience. World J Surg, 1998;22: 803-6. [CrossRef] [PubMed]

5. Hashim T, Chaudry AH, Ahmad K, Imhoff J, Khouzam R. Pneumomediastinum from a severe asthma attack. JAAPA. 2013;26(7):2932. [CrossRef] [PubMed]

6. Sakamoto A, Kogou Y, Matsumoto N, Nakazato M. Massive subcutaneous emphysema and pneumomediastinum following endotracheal intubation. Intern Med. 2013;52(15):1759. [CrossRef] [PubMed] 